\title{
Hmong Diaspora in Australia
}

\author{
Nicholas Tapp
}

\section{Introduction}

\section{A Brief Sketch of the Ethnic History of North Queensland}

North Queensland has been no stranger to ethnic variety and conflict. After the visits of early explorers, Leichhardt's expedition of 1844-45 had led to a much greater knowledge of the north. Almost every expedition to the region seems to have involved fatal skirmishes with aboriginal inhabitants. Overland squatters started to arrive from the $1850 \mathrm{~s}$ in search of pasturelands for sheep and cattle, and in 1859 Queensland was formally separated as a colony from New South Wales. Bolton (1963: 53) says that although aboriginal resistance had been successfully quelled within a few years of the coming of the white man, in 1861, incidents continued to occur. In 1889, Carl Lumholtz described how although 'the rough settler, who never sees a woman of his own race, soon begins to associate with the black women', real friendship is impossible: 'the white men shoot the black men, and the black men kill the white men when they can, and spear their sheep and cattle' (1889: 371). Dixon (1983: 53) describes the 
horrific nature of the 1897 Queensland Aborigine Protection and Restriction of the Sale of Opium Act, which authorised their removal into reserves, forbade them to buy liquor, marry or cohabit with whites without the permission of the Chief Protector.

Bonded Pacific Island labour was first used on the sheep farms and on the cotton and sugar plantations from the 1860s, although the traffic in 'Islanders' was widely condemned by missionaries. The first gold rush began in 1867 at Cape York, and increasingly over the next two decades prospectors for valuable minerals joined the early pastoralists. For some years settlers would divide their time between mining districts and canefields, but gradually a large number of ex-miners settled in the sugar districts (Bolton 1963: 303). A thousand Chinese overlanded from the south in 1867-68 after news of the gold find at Cape River, and then from 1875 immigrants from southern China started to arrive after Queensland gold reached the markets of Canton and Hong Kong (Bolton 1963: 55). Many of these Chinese migrants stayed on as cultivators, or as investors in cotton and sugar mills. Market gardening, of cabbages and lettuce, became a Chinese monopoly in the 1880s and 1890s (Bolton 1963: 222). They pioneered fruit on the humid coastal land between Cairns and Innisfail and maize in the more temperate Atherton Highlands (Bolton 1963: 229). By 1890, the Italians had started to replace Chinese as timber-fellers on the canefields and as charcoal burners (Bolton 1963: 160). By 1916 Italians outnumbered the Anglo-Irish by about three to one among the canecutters, from whom new sugar farmers were often drawn (Bolton 1963: 310). Dixon (1983: 106) describes one small Italian town (Dimbulah) whose main crop was tobacco, 'with a few fields of marijuana hidden away ...' . Japanese workers were also important among the canecutters, arriving in Geraldton (Innisfail after 1910) in 1889 after the suspension of Pacific Island labour, and then again in large numbers after 1921 when immigration to the United States was restricted.

North Queensland still had a reputation as the home of fearful diseases. In the first decade of the twentieth century the decline of mining left farming as the mainstay of north Queensland, with a high degree of specialisation; sugar along the 
coast, with maize and dairy-farming occupying the Atherton Tableland (Bolton 1963: 299-30). The Chinese began to lose their monopoly of Tableland agriculture after the Mareeba-Herberton railway was extended to Atherton in 1903. Slowly the early settlers were replaced; many Chinese left the district during World War I and the land was resumed by government for the settlement of exservicemen. As the sugar industry learned to do without coloured labour so the Atherton Highlands were developed as a white area with the influx of new settlers after 1907. It was the sugar industry which led to growing integration with the rest of Australia, and slowly non-European labour, including some Indian canecutters and the Japanese employees (Bolton 1963: 309), was eliminated.

North Queensland was firmly established as a 'white man's tropics' a hundred years after settlement (Bolton 1963: 323). Smallholder farming was well instituted and the system continued to appeal to migrant families from southern Europe (Bolton 1963: 325). The decay of Chinese banana plantations at Innisfail had attracted considerable numbers of Italian and Sicilian settlers during the 1920s, leading to fears Innisfail was becoming a foreign enclave. After the wounds of fascism were healed, in the 1950s more friendly local relations obtained with the Italians.

\section{And Another Tale ...}

Now let us tell another tale. At perhaps the time when Queensland gold was first reaching the ports of Hong Kong and Guangdong, attracting the first southern Chinese goldseekers to Australia, an upland tribal southern Chinese minority, the Hmong (devastated after their participation in several disastrous rebellions against the central Chinese state and in search of new lands to cultivate), slowly began to infiltrate into the mountainous uplands of the country which became part of the French colony of Indochina (Vietnam and Laos). As subsistence cultivators, and as the inhabitants of strategically important borderland regions, they were inevitably implicated in the struggle against colonial domination which was to become the Vietnam War, and which also affected large areas of neighbouring Laos. Hmong were drawn into fighting on both sides in this globalised conflict, for the communists, backed by the Soviet Union and China, and for the 
Western-supported struggle against communism in both Laos and Vietnam. Again Australia was involved. For, in 1951, an educational initiative, the Colombo Plan, ${ }^{1}$ was started with the assistance of the Southeast Asia Treaty Organisation (a strategic organisation set up to protect Southeast Asia from what was feared would be the 'domino' effects of communism in North Vietnam).

Some Hmong came to Australia under the Colombo Plan as schoolchildren at that time, part of a new breed of Southeast Asians the West hoped to encourage to fight communism. After the fall of Vietnam, and the subsequent collapse of Laos in 1975, tens of thousands of Hmong who had supported the American war effort in Laos flooded across the border into Thailand, and were settled in various refugee camps along the Thai-Lao border. From there they were resettled in many Western countries, including Australia. By 1985, 344 had settled here (Lee 1986); by 1996, the number was 1,421 (Lee 2001). Mostly they lived in Sydney, Melbourne or Hobart. The original Colombo Plan students who stayed on and who were familiar both with the situation of the Hmong back home and with Australian life, were crucial in assisting in this resettlement, advising the new arrivals, and interceding for them with the authorities.

In 1987, one daring and pioneering Hmong family went on a holiday to north Queensland from Sydney, and were attracted by stories of the profits to be made from banana plantations in the semi-tropical climate of north Queensland. They came up to Innisfail and indeed did well, leasing land and planting banana in the old sugar-cane plantations which had been worked by Italian immigrants (see also Lee, this volume). They were probably not aware that they were reviving the practices of immigrants from the same part of the world — southern China - a century before. But they will have known that in Laos, Thailand, and in Vietnam too, the Hmong often grew bananas in small plantations around the homestead and the village. Attracted by their success, many more Hmong families from Sydney moved up to Innisfail and invested in land. Some moved later to Cairns, and these north Queensland Hmong were joined in the early 1990s by other Hmong from Victoria, since which time Hmong have moved in from Hobart and elsewhere in Australia, and even New Zealand. 


\section{The Research Visit}

In November 2002 I accompanied Dr Gary Lee, one of those (like Dr Pao Saykao in Melbourne, and Vw Thaow in Hobart) who had originally come to Australia under the Colombo Plan, and had subsequently been instrumental in helping many of his fellow countrymen to settle in Australia, on a research visit to Cairns and Innisfail, after a previous research visit to the Hmong community in Melbourne. This visit was funded by the Chiang Ching-Kuo Foundation in Taiwan, and formed part of a larger research project which involved the study, not only in Australia but also in Thailand, Laos and southern China, of the new transnational contacts being formed between Hmong who, after their flight from Laos, had been scattered across the continents of the world. The aim of the project was to examine the return visits of overseas Hmong to their old homes in Southeast Asia, or even to the more distant homes of their ancestors five to seven generations ago, in southern China, to see what impact these visits and their new global relationships were having on specific locations in Thailand, Laos and China. In a future extension of the project it was planned to include Vietnam, Canada, France and the United States.

By examining the economic, cultural and social transformations of localities resulting from these returns of diasporic minority migrants, the project intended to contribute to Chinese diasporic studies, which had rarely included studies of ethnic minorities, nor focused on the return visits of overseas migrants to Asian homelands. It was hoped that our research would result in a new model for the integration of local with global data, and that it might also contribute to more general debates about the romantic sources of modern individualism, the nostalgic consumption of local 'roots' as commodities, and the significance of structures of local desire in constituting transnational identities through the formation of cultural strategies by the members of new social movements, or what Werbner (1996) calls 'communal diasporic voluntary public culture'. Besides testing what we had already learned in Asia about the impact there of overseas Hmong, we had also been testing the major hypothesis that the Hmong were forming a new kind of transnational community through 
international visits, marriages and telecommunications such as the internet. We interviewed a large number of people, and this chapter represents some of the results of that research in Innisfail and Cairns, with some reference to comparable materials collected in Melbourne.

\section{North Queensland}

\section{General Introduction}

During our fieldwork in north Queensland, we spent most of the time in Innisfail, where there were $70 \mathrm{Hmong}$ families with a total population of approximately 450. Thirty-five (now 23) of these families leased or owned plantations (mostly of banana, but some specialised in papaya, lemongrass, ginger or sweet potato for the Asian market, and there was a significant amount of poultry and pig keeping), having moved up from Sydney and elsewhere since the early 1990s. ${ }^{2}$ Other jobs in the community ranged from Christian pastor to housing association worker, banana packer and cook in Chinese takeaways, steel welder or hired plantation labourer, and there is a low rate of unemployment compared with other Hmong communities. ${ }^{3}$

Cairns is the big city, and port, in this region, and Innisfail a somewhat sleepy coastal town into which the Hmong seem to have fitted without much outward difficulty. As Bolton (1963: 334) remarked, the fusion of Italian with Anglo-Irish immigrants has been so successful that one may only glimpse it in the good quality of the bread at Ingham and Innisfail, and the roving eyes of the young men as they prowl the streets of sugar towns in the evening. An elderly local resident still remembered when as many as a third of the town's population had been Italian. The Hmong live in suburban houses of varying size and status, and manage their farms in the country through daily visits.

The Hmong community in Innisfail (which had a population of 20,800 in 1996 if the surrounding rural areas of Johnston Shire are included), enjoy generally good relations with the local community, as the ex-President of the Hmong 
Association (Xao Lee) explained to us. During his two-year period of office he had made efforts to contact the local council, the police, the hospital and other public agencies, about the Hmong community, and this seemed to have paid off well, for example in terms of some support received from the local council. The main points of contact for the Hmong community with the wider society were through the local Multicultural Officer, who visited regularly, and through the Mayor of Innisfail. The local population was composed of Italians, Greeks, and Indian banana farmers besides those of Anglo-Irish descent, some Macedonians and Yugoslavs, and still the remnants of the South Sea Islanders originally hired as canecutters by Irish plantation owners.

The former President stressed to us that there were bound to be some problems within the Hmong community since, as he pointed out, it is composed of the members of radically different social strata from Laos: ex-soldiers, ex-farmers, and ex-students. He saw one of his main tasks as explaining to the older members of the Hmong community the relevance of Australian laws as opposed to traditional attitudes 'like the idea that you can beat your wife, or kill her lover'.

He emphasised how few problems there were with other local farmers - the farmers all stick together, and help each other, he said. There were sometimes problems with neighbours, he admitted, particularly over the large gatherings the Hmong sometimes have for ritual or ceremonial occasions. For example, there must have been over a hundred people at a shamanic session (ua neeb) we attended, and the whole road was jam-packed with Hmong cars. 'I do think some parts of our culture may just not be suitable for the life here', he confessed. Sometimes there were other small problems, over kids picking fruit, for example. But the majority of people were 'okay', and the Hmong here always took pains to inform neighbours beforehand when major social events were to occur. In striking contrast to the ethnic violence and conflict which seems to have characterised the area, therefore, the Hmong today appear to live in an open and largely accepting society. Local non-Hmong residents confirmed this view of things.

Owing to the small numbers of Hmong in Australia, clan organisation does not seem to have adopted the radical forms it has 
in countries where there are much greater population concentrations, like the United States where over 180,000 Hmong now live. Instead, local associations have been initiated which are not exclusively clan-based and, as we were told with some pride in Innisfail, it is customary to invite members of other clans to weddings and ritual events, unlike what is felt to be the case in the United States or elsewhere. American Hmong, they feel, are 'not friendly, in the words of one informant.

Although many moved to north Queensland with clear hopes of commercial gain, the Hmong who first settled in Innisfail must have been the pioneers, the far-sighted yet nostalgic ones who had not yet lost sight of their farming backgrounds in Laos, and had hoped to revive them by moving into this region. It was by no means everyone among the Australian Hmong who came to Innisfail, yet those who came must have been in some way dissatisfied with their previous urban existence (jobs reported in Sydney ranged from making window-frames in a factory to carrepairing) and longing, in almost a New Age way, for a more substantial life. One old man at a shamanic session told me that banana farming was a bit like life in Laos had been; although it was hard work, at least your time was your own, and you could rest when you liked. The Innisfail community is today seen as conservative by other Hmong, particularly those from overseas countries, and this may be a reflection of the way the Australian Hmong are generally viewed by those of other Western countries. One Hmong woman from France, who had moved to Melbourne to get married, talked of her attraction and shock to discover how 'strict' and 'old-fashioned' the Hmong here were, and this she said had given her a sense of security, a sense of 'coming home'. ${ }^{4}$ Certainly the need to live together in a large (coob) group has been important in the many secondary relocations which have taken place since the Hmong first arrived in Australia (and secondary relocation of large groups has also been a phenomenon in France and the UnitedStates). This was one of the main reasons given for why all fifteen Hmong families settled in New Zealand had recently moved to Innisfail, together with the lack of ritual specialists. In one case a body had to be sent to the United States 
for the proper death rites, owing to the original sons of the deceased having settled there. This scarcity of ritual specialists remains a very real problem for the Australian Hmong, who now number nearly 2,000 .

The 'sucriers' or baby bananas of Indonesian origin in which they tend to specialise, I was told, are mostly sold to Asian vendors, and it was the need for these to be altar offerings for the Vietnamese in Melbourne which led to the original demand for them in that city. There are of course hundreds of strains from Laos which could be planted here, and which might sell more successfully, but in general Australian restrictions on imports of organic produce are too stringent for them to have attempted this. Other Asians besides the Hmong and Vietnamese prefer the 'Daccas' while Westerners prefer the larger Cavendish which sell in supermarkets. We visited one farm of 66 acres, the next one had 40 and that was also the size of our host's.

However, most families are now beginning to sell their farm leases off and discussing a further relocation to Brisbane or other places. Today there are Hmong communities in both Cairns (predominantly Christian Green Hmong who had arrived later in Australia) and Innisfail, and Cairns is now attracting an increasing proportion of the youth from Innisfail in search of new work opportunities, as we see below. And there are separate local Hmong associations; the Innisfail-based North Queensland Hmong Association, affiliated to the national organisation of the Hmong Australia Society (see Lee, in this volume), which includes members of the cultural Hmong Federation based in Cairns as well as the SPK housing association there, but not of a break-away Hmong Council also based in Innisfail. ${ }^{5}$

\section{Data on Return Visits}

Exogamous patrilineal clans are pivotal in Hmong social organisation, and in the following I consider population figures according to their breakdown by membership of different clans (Xyooj, Tsab, Yaj, and so on). ${ }^{6}$ In Cairns, at the time we visited, there were seventeen of the Xyooj clan in three families, 106 of the Tsab in sixteen families, 41 Yaj in seven families, 14 Lis in two households, 15 Hawj in two, $18 \mathrm{Kwm}$ in three, 24 Vaj in four 
households, eight Muas in just one family, $32 \mathrm{Vwj}$ in three families, and 28 Thoj in five families; that is, a population of 303 , in 47 households. Household size ranged from two to eleven, with an average of 6.4. In Innisfail (excluding approximately $87 \mathrm{Hmong}$ Council members - some 40 adults - for whom this information was not available), there were 56 of the Vwj clan in eight families, 40 Lis in six households, 25 Xyooj in four households, 16 Lauj in three, three Muas in one household, $96 \mathrm{Vaj}$ in twelve households (although one of these was headed by an inmarrying Cambodian male), and 93 Yaj in fifteen households; that is, a population of 360 , in 49 households. Household size also ranged from two to eleven, and the average household size was 7.3. ${ }^{7}$

The cases of returnees to Laos and visitors to other countries which I give below, covered the total Innisfail Hmong population, including the Hmong Council members excluded from the figures above.

The data collected from Innisfail on returns to Laos was extremely accurate and meaningful and can in my opinion very probably be generalised to other Hmong communities in Australia, although it must be recognised that it represents the maximum extent of contacts with the homeland to be found in any Hmong community in Australia; that is, there were more contacts with the homeland here than there would be among any other Hmong communities in Australia. From that data, including Hmong Council members, out of exactly 134 adults of over eighteen years of age in Innisfail, only 31 had been back to Laos at all. This percentage (23.1 per cent) would of course diminish considerably if we considered it against the total Hmong population in Innisfail of 450, and would diminish even further in other locations in Australia. But it is surely significant that as many as nineteen out of these 31 visitors (over half of them) had not only visited Laos, but had also made visits to Hmong communities in the United States, while in addition to the 31 who had revisited Laos, a further 28 had visited the United States without undertaking any visits to Laos at all. In other words, an overall total of 59 adults, or nearly half the total adult population of 134, had undertaken overseas visits to Laos or America. And visitors to 
the United States (47 altogether) well outnumbered those to Laos (31). The figures are even clearer when one considers the number of total visits made, since often more than one visit was made; the total number of visits to the United States, as against visitors, was 66, whereas only 38 visits altogether had been made to Laos.

To anticipate our conclusions, it did seem, from both this and other evidence, that more linkages are being formed between Hmong in First World countries than are being formed between First World and Third World Hmong, and that, as we show below, rather than any single or unitary Hmong community emerging internationally, through modern communications and transport, a number of very different appeals are being made to that imagined sense of unity.

Ages of visitors to Laos were almost invariably over 40; only five out of the 31 were under 40 years of age. The 31 cases of adult Innisfail Hmong who had been back to Laos includes nine wives who had been accompanying their husbands, and one divorced couple who had both been back to Laos separately to remarry (we met the second wife of the man later in Cairns at Rusty's Market, where several Hmong women make a good living selling fresh fruit and vegetables). They also include a mother and daughter who had visited together, and the sister of one of the nine wives who had accompanied her and her husband, all for medical reasons. Two out of the nine couples had travelled together making up a group of four, and one other woman (a friend) had accompanied one of the couples. None of these visitors had taken their children back to Laos, but two of those who had also visited the United States had once taken their children there with them.

Four of the Laos returnees had made two visits; so had the mother whose daughter had accompanied her on one of these visits, as had the wife whose sister had accompanied her referred to above, and also the divorced wife also referred to above. Of the first four who had revisited Laos twice (which was the most times anyone had been back), one had been looking for a wife in Laos, and had also visited the United States, one had been looking for a wife in Laos, and had also visited France; another had also been looking for a wife in Laos, but had not been to any other countries, 
while the last case had also visited the United States, but had not been in search of a wife. The mother whose daughter had accompanied her (on one of her two visits to Laos) had also visited the United States; so had the wife whose sister had accompanied her once, and who had adopted a child in the United States (see below); and so also had the divorced wife who was in search of a new husband. Out of the nineteen of these visitors to Laos who had also made visits to the United States, two had made two visits to the United States, and three had made three or more visits to the United States (including the couple who adopted the American child). Out of the 31 who had revisited Laos, fourteen in all were women (including the nine accompanying wives, the divorced wife, the mother and daughter, the sister of the adopting couple, and the friend of the accompanying wife).

Of the 28 cases who had visited the United States, but had made no return visits back to Laos or Thailand, nine of these were also wives accompanying their husbands - although one of these accompanying wives had originally come from the States - and there were four other married women who had been to the United States without their spouses; one to see close relatives, one to see her parents, one to see her daughter. At least four of these cases had taken their children with them to the United States; four children in three cases, one daughter in the other. Four out of the 28 had made two visits to the States, one had been there three times, and one had been four times (the husband of the woman who had made three visits). The wives of three of the four men who had made two visits to the United States had only visited there once (including the wife who had originally come from the States). Ages of these United States visitors were not collected.

Apart from the divorced couple, who had both found new spouses in Laos, two of those who had revisited Laos had successfully found wives there - both of these were among those who had visited Laos twice, and one was the one who had also visited France (the only case of a visit to France in Innisfail). I have mentioned above the other case of a man who had been to the United States twice, but not to Laos at all, and whose wife came from the United States. ${ }^{8}$ 


\section{Reasons for Returns}

The explicit reasons for return visits to Laos varied widely; apart from the elderly divorced couple referred to above, who both contracted successful marriages with Hmong from Laos, three other men had gone back to Laos explicitly to find a wife. One shaman had revisited 'for cultural reasons'. The most common specific explanation was 'medical' in nature; the mother and daughter pair referred to above had been back for medical reasons (kho mob), as had another couple. The two couples who had travelled in a group together had all gone for medical reasons, and so had the wife and her friend who had accompanied her and her husband (that is, a man went back with his wife and his wife's friend who were both travelling for medical reasons). One of the other couples who revisited had also done so for specific medical reasons to do with fertility; it is quite often the case that couples who are unable to bear children may feel that only a special shamanic session in Laos or Thailand may help them, or particular types of herbal medicine (tshuaj ntsuab) which can only be obtained there. In my travels around Thailand the previous year with a visiting Hmong couple from the United States, medical reasons had played a part in their visit; they had particularly wished to consult a certain shaman who lived in the north of Thailand, and showed a great interest in various herbs and spices which we found in Hmong villages along the Lao border.

In one very sad case among the above revisiting couples from Innisfail, the sister of one wife who had accompanied her and her husband on one of their visits had done so specifically because her sister was unable to have a child, and this was also the reason for the couple's visit. This couple had also visited the United States several times (the husband had accompanied his wife three times, and she had made two further visits alone), in order to adopt her sister's child from the United States (her sister was settled in the United States), having failed after a number of tragic years in their efforts to adopt a child from another country. This adopting couple was a very special case, and yet in their story one can see something of the way Hmong kinship relations (see below) can often work to support individuals in difficulties across the oceans. 
They had spent years trying to adopt a child since their first arrival in Australia in 1979. Her own parents had been resettled in the United States, together with her two sisters and two brothers, where her mother had remarried, so that effectively all her own nearest relatives were in the United States.

In 1986 she and her husband had visited Korea with the intention of adopting a child but were finally refused, she said, both because they were classified as 'animists' rather than belonging to a 'proper' religion, and because she could produce no Australian Higher Education Certificate (how could she have done?). It was too difficult to arrange an adoption from China, and Taiwan was also ruled out because they were not Christian (she refused to convert simply in order to make adoption easier, she said). So her younger sister, in the United States, who had already had some children, 'got pregnant for me', but then she had miscarried.

Then, in 1996, this American Hmong sister 'had my son for me again', she said (using the name of her current, adopted son, referring implicitly to the Hmong belief that repeated miscarriages are caused by the playful returns of one naughty or wilful child). They had both gone over to the States for the birth, but had then had to return again to Australia after a month, and had finally managed (after another visit to the States by herself) to bring him in here as her nephew, although in Hmong eyes this was clearly a son she had adopted.

She told us the sister had 'had the child for her the second time' because her eyes kept streaming in a strange way for three months and finally she had exclaimed (to an unspecified deity) 'If you want me to have this baby, stop my eyes streaming!' — and the streaming had suddenly and inexplicably stopped. Her sister had still missed the child terribly, she said. The boy turned out to suffer from a mild autistic condition, and it was this which had led to their subsequent visits to Laos to find a shamanic or herbal cure for his condition (which was now finally improving). There are of course no formal arrangements between Australia and the United States for individual adoptions of this kind, so that now her boy was approaching school age it was imperative to formalise the 
adoption, and this was proving to be a legal nightmare. Their banana farm had been sold and they were considering relocation to the city with her son's future education in mind. This was a very special, and sad case, and the reason for repeating it here is that it makes the point (as Dr Pao Saykao in Melbourne had also stressed to us) that most people have very specific reasons of their own for going back to Laos or Thailand, and the case also underlines the importance of these so very recently severed kinship ties across the globe (see below).

Besides 'medical reasons' of various kinds, the other main reason given for revisits to Laos was in order to see relatives. Probably every case in the 31 had visited relatives of close or near distance during their revisits to Laos or Thailand, but two cases had gone specifically to see relatives for particular reasons, another had been back to see his mother when she became very ill, and another specifically to see his parents who had been repatriated back to Laos from Thailand in about 1995. Reasons were, therefore, quite specific and personal, and overwhelmingly linked with family and kinship (see below, The Importance of Kinship). For example, one man from Cairns had revisited Thailand in order to assist in the wedding of a classificatory nephew to a local Hmong girl (originally from Laos) whose parents were demanding an outrageously high wedding payment of some one hundred thousand baht. ${ }^{\text {? }}$

In our previous research in Asia, on the local impact there of Hmong who were visiting from overseas locations (such as Australia), we had found a variety of motivations besides simple nostalgia given for these visits. For example, in Wenshan prefecture of China, close to the Vietnam border, which is regularly visited by overseas Hmong (overwhelmingly from the United States, as was the case in all the Asian locations we visited), five broad categories of overseas Hmong visitors had emerged from our interviews with local Hmong, and with those who were visiting from overseas; the most important and primary reason given for return visits was the wish to visit relatives or to discover family links and original places. This probably plays a primary part in almost all overseas Hmong revisits to Asian locations. But in addition to those who visited 
primarily for reasons to do with kinship, there were also those who came back 'for business reasons'; with hopes or plans of establishing international business and trading relations through local Hmong links.

Other categories of visitors included: religious missionaries, since there are quite a number of Protestant Hmong in the United States attached to various churches who revisit for the purposes of proselytisation, some Catholics or members of other religious organisations; and also political emissaries, those in the cause of General Vang Pao, the retired Hmong General from Laos now resident in the United States, who supports and sponsors factions of an ongoing Hmong resistance in Laos. Finally, very commonly among the overseas visitors have been those who are in search of love, or second wives, sometimes after divorces overseas, sometimes by those who are already married (since traditional Hmong culture allows second marriages by men). Local reactions were very mixed towards these overseas Hmong, whom some Hmong in Australia (and Thailand and China) said tended to be those who had not adjusted well to their new lives overseas, were out of work and going back to impress, and serious local problems had emerged regarding all these categories of overseas Hmong visitor except the first (the ones who visited purely for family reasons). It was the last ('love') category, where problems seemed to have been most acute and were most discussed. It is quite common, for example, for Hmong men from overseas to revisit Thailand, Laos or even China at the Hmong New Year, and to start a local affair with a Hmong (or in some cases Chinese) girl, which they have no intention of formalising into a marriage, perhaps because they already have a wife overseas who knows nothing about it, and there are many stories of these kinds of deceptions and a certain amount of local anger about it.

Some of these more regular visitors, particularly from the United States and France, keep effective concubines in Asian locations whom they visit regularly and provide some support to. 'Hmong men just go back for fun,' said one teenage informant in Melbourne dismissively. On the other hand, this kind of liaison cannot occur without some local complicity. When I visited the 
Hmong settlement in Thailand where the high bridewealth case referred to above occurred, local Hmong leaders told me that people were generally wise now to these sorts of tricks (and this was why high wedding payments were sometimes demanded when an overseas Hmong offered to marry a local girl), but some of the young girls just did not care if they were exploited, they said; they just went with visiting American Hmong for the sake of money or other benefits, not expecting marriage or a permanent liaison, and would not listen to the injunctions of their parents and elders! This was a different kind of youth recalcitrance from that of the young Hmong people in Australia in their wholesale rejection of, or disinterest in, Hmong cultural traditions (see below), but similarly distressing for their parents.

\section{Overseas Marriages}

A number of international marriages had taken place, although less in Cairns/Innisfail than in Melbourne, some of these based on previous contacts through the internet. In Melbourne we had interviewed members of one somewhat extraordinary family with one brother in France and one in the United States who maintained extensive contacts through visits and a dedicated family web page and information bulletin. Two brothers, who lived together with two other brothers in a large extended family in Melbourne, had married Hmong girls from France, while a third had had extensive internet relationships with girls from overseas. As the latter put it to us, he had been twice to the United States to visit girls, each time a different one, and one American Hmong girl had come here specifically to visit him. In each case he had chatted online with them and exchanged emails with them for periods of time ranging from several years to six months to a brief exchange of emails before their actual meetings had taken place. He said he had also had some real-life romances in Australia, but was very gloomy about the chances of finding a wife here. He complained that the 'supply' of girls here was too small, and there were none older than 21. 'The girls are dying out!' he exclaimed. Of course, his assumption was that he should find a Hmong mate, and this we found to be a very general one. Besides these cases, one (Thoj) girl had gone to the United States to find a husband and had 
settled there, one American girl had visited and married (a Xyooj) here, one (Yaj) man had found a wife from Fresno, and there was one case of a wife being found from Laos after divorce.

In Innisfail there had been three cases among those we recorded of men who had gone back to Laos/Thailand explicitly to find wives, besides the divorced wife who had found a new husband there, and the case of the nephew in Cairns noted above. Apart from the case of the visitor to the United States whose wife had come from the States, one other girl in Innisfail had also married there (Tooj Xeeb Yaj's daughter). A further three girls had married Australians, and one girl had gone off to Ireland with a backpacker she had met locally and married. Despite a general disinterest in Hmong culture and history among Hmong raised in Australia, or under 40 years of age, which we examine in more detail below, the preference is still very much to marry Hmong spouses. We were told that it was relatively common for a boyfriend or girlfriend to be an Australian, but marriages were overwhelmingly with other Hmong.

The girls we interviewed were understandably somewhat circumspect about their use of the internet to find potential marriage partners. 'We are aware of the Hmong in other places,' said one, delicately. In practice, however, these are as likely — if not more likely — to be in New South Wales or Hobart as overseas. 'There are so few Hmong here,' said one teenager, 'most girls are looking for Hmong lovers on the internet and wanting to go to the US.'

It seems that while the internet is used as a means of meeting other Hmong, not only overseas but also across Australia, by the younger people and teenagers, where international marriages do take place, they may generally tend to strengthen Hmong custom and tradition. One informant in Melbourne, for example, had married a Hmong from France, whom he had met here, whose parents had subsequently been unable to join them in Australia; at the time they married, his Hmong was falling away as he was more used to speaking in English, while her French was very much better than her Hmong. Now, however, they usually speak Hmong to each other.

In another interesting case there, a young schoolgirl who had just begun to enjoy the internet and was speaking English 
better than Hmong, had been married off reluctantly at a very young age to a much older man from France, but had since then become an explicitly contented, fairly traditional Hmong wife. 'I am an innocent girl and my husband is much older and knows many things so I have to trust him and look up to him and obey him. To start with I was quite angry but after I knew his family and relations it was better. You have to get to know someone ... nws paub lus' (literally, 'he understands [peoples'] words', or 'he knows stuff', that is, is mature). The few international marriages there had been seemed therefore to play some part in maintaining Hmong cultural traditions which were otherwise dramatically weakening.

Internet usage, however, had had to stop with her marriage. Recently there has been much talk about the terrible case of $\mathrm{Pa}$ Shia, a well educated young Hmong wife in California who spent so much time on the internet that her husband became jealous and tried to stop her. 'Only if you kill me will I shut up,' she is alleged to have said, so he did shoot her, and himself, and their children (he survived; see discussion on Hmong Social Cultural Group 2000).

There seems less interest in Innisfail than in Melbourne in finding spouses overseas or using the internet for that purpose, and one cannot help wondering whether this may be related in some way to the high rate of visits back to Southeast Asia among the north Queensland Hmong by comparison to other Hmong communities elsewhere in Australia.

\section{The Importance of Kinship}

Reasons connected with recently severed kinship ties have been fundamental in bringing Hmong visitors back to Laos and Thailand, and even in visiting other Hmong communities in the United States, where almost every Hmong in the community has at least one close relative, and we have seen something of the strength of close family ties across divided continents in the case of the child adopted from the sister described above. The important role played by kinship in the global ties now being formed between the diasporic Hmong community was impressed on us in a number of ways. One Innisfail family showed us a questionnaire entitled the 'United Yang Family Survey 2000'. The survey had 
been prepared in the United States, and is being distributed among all Hmong members of the Yang clan globally. It asks for information (in Hmong and English) on religion (old or new) and leadership experience (kev coj noj coj ua) besides educational level, occupation, and details of wife and children. On the back of the form there is a skeleton genealogical diagram for ego's generation and four ascending paternal generations, and the brothers and sisters of each, with the names left blank to be filled in. Here an appeal to Hmong global unity was certainly been made, but purely on a clan basis.

In the huge house of one banana farmer, whose wife's brother also has a plantation, we were told how he worked hard from dawn to well past dusk every day on his 70 acres and how the price of bananas had fallen from 25 dollars to 15 per carton since 1995-96, when they had moved up from Sydney, where he had been working in a factory making picture-frames. He was now thinking of selling up. With relatives still in Laos and a brother still in Wat Tam Krabok (the famous Buddhist temple in Thailand which houses many Hmong refugees from Laos), an incredible family reunion had taken place earlier in the year. His sister, whom he had not seen for two decades, came from France, together with the husband she had married in Thailand but whom he had never met, and their children. His mother's sister had come from France, as well as his father, who had exited Laos later than he had and was now settled in the States with a new wife, and also his mother, who now lived with her brother in Sydney, and a married sister from Sydney, making up a joyous party of ten. This informant was one of those who had visited the States together with his children since, as he said, his main motive for the visit was to have his children know their cousins and other relatives there. He had also been back to Laos with another couple and his wife who had a bad back, where he had visited a famous shaman. However, the visit to Laos had not gone well; they had only been allowed five days there and had had to bribe the local police for that. One of the reasons why more visits to the United States may be occurring is the practical difficulties for many Hmong, particularly those blacklisted as previous reactionaries, of getting into Laos at all. But these sorts of reunions of globally dispersed families can only rarely happen. 
The primordial importance of kinship in the visits Hmong make back to homelands as well as to new Hmong communities in other First World countries, and as perhaps the major factor unifying the globally scattered Hmong, was much impressed upon us through this visit. One key informant in Melbourne had remarked how he thought the Hmong already had virtual families, and that now they needed to establish a global virtual community. The internet is of course one key way in which to do that, and although its use and frequency was less than we had expected when beginning this project (since many families do not have internet access nor the ability to use computers), it did seem that it might be fulfilling something of the same functions as the kinship system did when the Hmong were divided from each other through their traditional lives as shifting cultivators.

\section{Economic and Other Relations Overseas}

Almost all of those who still had relatives in Laos or Thailand supported them financially. It is difficult to obtain accurate figures of these very personal payments among different families, but our research in Thailand and Laos, and also China, had already alerted us to its significance and given us some idea of its extent. In Innisfail informants estimated the average sent back by particular families in Laos or Thailand annually was around the A\$500 mark. One ritual specialist told us of his two sisters in Laos whom he had supported regularly for a number of years. He planned to return to Laos next year specifically to help his sister build a house which he thought might cost the equivalent of US\$9,000 in all. He calculated he sent as much as $\mathrm{A} \$ 3,000$ a year back home, in small amounts of a few hundred a time. Another informant sent about A \$400-500 each year, to both Laos and Thailand but predominantly to Laos, especially at the New Year. His wife and children also helped relatives from Laos, now in Thailand, sell $p a j$ ntaub (Hmong traditional embroideries) for them and sent back perhaps A \$700-800 each year to them. We were told that almost everyone, or at least 90 per cent of the community (meaning household heads) sent something back to relatives in Laos or Thailand, ranging from $\mathrm{A} \$ 500$ to $\mathrm{A} \$ 3,000$ in any single month, usually in small batches of hundreds and mostly for specific 
occasions, such as a funeral, sickness, the repair of a house, or the New Year.

Besides these regular remittances sent back home or to relatives in Thailand, which are a constant drain on the resources of newly arrived displaced persons and recently resettled families, but have a far-reaching impact on local communities in China and Laos as we have witnessed, other economic relations with Hmong overseas were in general less than we had expected, although they do exist and they are important.

One Innisfail man with family in Sydney, Brisbane and Canberra, had a part-share with another family member of a grocery-cum-boutique store in St Paul, Minnesota, managed by affinal relatives there. This was a properly run and genuinely international business involving buyers from the United States visiting Thailand and international taxation agreements. ${ }^{10}$ Yet these enterprises are very much the exception, and most overseas contacts of an economic nature are likely to be through the smallscale family-based traditional costumes industry, with relatives in Thailand sending products which may be finished overseas and sold elsewhere, through the circulation of Hmong videos, produced by American Hmong often in Southeast Asian locations with local Hmong assistance, which occupy the nostalgia and time of the elderly, or through remittances sent back to relatives in Laos. Other contacts overseas included, for example, fairly extensive visits made by a Christian pastor in Melbourne for training courses in Thailand, and regular visits to him by American pastors of the Christian Alliance Church (see www.hmongdistrict.org) and the housing association in Cairns planned to link up shortly with overseas Hmong organisations.

\section{Dissatisfaction Among Youth}

It may fairly be said that the Hmong are in cultural crisis, with the elders alarmed at the loss of Hmong culture by the youth, and some of the young men in Melbourne very concerned about the lack of eligible Hmong spouses who tend to marry early. Many of our informants feared or felt that the Hmong would 'disappear' (ploj) as a people within a generation if these trends continued. 
The attempt to revive a traditional agrarian life in Innisfail has not, overall, been a success. Banana prices have fallen owing, it was said, largely to the increasing numbers of people joining the business and the rising prices of chemicals and diesel fuel. On the roads we saw bananas advertised at one dollar per kilogram-bunch, but we were told a 13-kilogram carton had previously fetched up to sixty dollars in Melbourne. There was general agreement that the children hated to come to the farms, feeling that farmwork is too 'dirty', and there are few work opportunities locally for the younger generation. The younger generation are, inevitably, dissatisfied, as it is said those who had been resettled in French Guyana and successfully adopted a farming life are, and now many of the banana farmers are talking of selling up and moving to Brisbane. There has been regular annual movement of families to Cairns as children left Year 12 of schooling to find work in town.

Many of the younger Hmong feel only a faint curiosity towards their own backgrounds and cultural heritage. One 16-year old girl said of Hmong custom and tradition, 'my view is we won't need it, when we go into the real world'. As she said, she was 'not very interested in Hmong culture', but liked softball and netball. 'My Hmong now is not too good,' said an 18-year old TAFE college student, 'you probably need to understand the culture, to speak the language ... Kevcai - probably very interesting ...' Another married man of 30 with young children complained that with both he and his wife working and the children at the Day Care Centre all day they had almost no chance to speak Hmong with them, so the children knew no Hmong. He had no feelings at all about going back to visit Laos, and didn't know how he would cope there with no toilets or clean water to drink or shops down the road. His family had no religion, he said, but just followed his father who was a ritual expert. If his kids wanted to learn about it, he said, they could ask their grandfather who they saw every weekend or so. 'Sure - Hmong kevcai [customs] will disappear. I don't have any knowledge of it, and I won't force my children to learn it. I choose not to know about it — so it will die! If you believe it, it must matter I guess. It's too late for me to learn about it, or want to learn about it, and I don't have much interest in 
wanting to learn about it. From what I understand, funerals are the most important kevcai, and I just want there still to be kevcai so when my father dies he can have that, but after that I don't mind.'

Those of the older generation are sufficiently concerned about this lack of cultural competence among the youth to have started a variety of cultural transmission attempts, and there are now active attempts to keep Hmong culture alive by teaching it to younger people in centres in many different countries, including Thailand. In Melbourne we had visited one centre where 15-20 men, none too young, were learning the Song of Opening the Way which is sung at a death (qhuab ke), how to call the soul ( $h u$ plig), and perform ancestral domestic worship ( $u a$ dab xwm kab) and the wedding songs (zaj tshoob), and another informant organised his own regular sessions at his home. Attendance seemed fairly desultory and there was an air of artificiality about these places; but it must be remembered that these traditional skills and competences would normally have been passed from a parent to a child, or from a Master to a disciple, and their transmission in the public arena marks a real sign of concern about the perceived loss of cultural heritage and a real recognition of the efforts needed to maintain it.

\section{Messianism and Nationalism}

There is also one tendency which continues this desire to resuscitate traditional Hmong culture in a bizarre form disliked by almost all the local Hmong. The original pioneer, who had moved up to Innisfail from Sydney to initiate the first Hmong banana plantation, had squandered his new-found wealth through various means, lost his land and was then reduced to watching other Hmong, who had followed his example and moved up to Innisfail, making good where, it seemed, he himself had failed. After an abortive attempt to immigrate to the United States, and a venture into the restaurant business, he became a member of a new religious cult founded by a member of another clan who had unsuccessfully struggled with the local pastor for control of the Hmong Christian community (see also Wronska-Friend, this volume).

This novel religious movement has now established a temple and a priesthood, has created new syncretic beliefs and 
rituals (including Christian-like prayers before meals, watersprinkling before visitors enter their houses after the fashion of Buddhist monks, and bowing in Japanese fashion before making offerings) and is applying for government funding under the name of the Amu. This is a composite name based on readings about other Miao groups related to the Hmong in China known as the A Hmao and the Hmu, which the cult adopted after local Hmong refused to allow them to use the name of 'Hmong' to represent their beliefs. Their ritual leader (the ex-Christian) is also a (selftaught) shaman, although the shamanism he practices is said to be very strange and unlike that of others. The cult is fire-walled by ritual beliefs in pollution and fear of contamination by the 'earthly' world, particularly by those Hmong who do not support them. It is said that the pioneer joined up with this movement after reading a book published by a local canecutter who claimed to have been taken on an extraterrestrial voyage in a UFO where he had met the Hmong well before they had arrived in Innisfail.

The sect claims to hold the secrets to a variety of world mysteries, such as the pyramids and Stonehenge, and allows intermarriage between members of different patrilineal clans. This is a Hmong, but also a New Age spiritualist movement, and its members talk easily about auras and astral bodies in true 'Madame Besant' style. They retreated from the rest of the Hmong community before the year 2000 when various floods and disasters were promised, equipped with stockpiles of rice and petrol. In common with other historic Hmong movements of resistance against established authority it is messianic; that is, it believes that a saviour will be (in fact, now has) been born who will become the Emperor of the Hmong and lead his chosen people to salvation. The ten members of this cult (four families from Innisfail, including two who had previously been members of a Chinese vegetarian cult) have retreated to the Atherton Tablelands, some 2,000 feet above sea level, rich dairy country and the site of remote early cattle stations, where they practice a modified form of vegetarianism and wear a rather remarkable form of traditional Hmong costume.

We interviewed members of this small New Age community in Atherton, all of whom, I was told, are on welfare 
payments. The cult leaders have close relations with a Hmong messianic movement originally started by Yaj Soob Lwj, which flourished in the refugee camps along the Thai border and supports the 'Chao Fa' resistance leaders in their doomed battle against the Pathet Lao authorities. There are frequent visits to Thailand to consult members of this movement and it may be seen, therefore, as a global as well as a local response to cultural pressures upon the Hmong community. One Hmong in Melbourne said that he had received a telephone inquiry from some Hmong in China who wished to know if the rumours that a Hmong King had been born in Australia were true since they feared the Chinese government would try to assassinate him!

Although this movement is an embarrassment to most right-thinking Hmong (who wish the Hmong to move forward in their history, see the movement as a regression and its leaders as those who have failed to adjust to their new lives in the West, and would probably prefer it not to be written about), I see it as an important minority attempt to retain a form of traditional culture which most Australian Hmong are, inevitably, losing. The fact that it is not traditional culture at all, but a new form of custom and belief, is in itself an important (and creative) response to almost overwhelming cultural pressures to assimilate and acculturate. It is a kind of refusal to acculturate, and an attempt to impose a form of minority culture on the Australian consciousness in the only way that our society is prepared to tolerate radical cultural differences — as a fringe religious cult.

Although the movement is so small, and cannot therefore be taken as representative of general trends among the Hmong community in Australia, such attempts to cling to or revive traditional culture are not confined to this movement alone nor are they the preserve of an older generation which has found it difficult to adjust to the life overseas. This was shown in the case of one young man we met who has invented a new Hmong national flag along traditional symbolic lines and told us that he wishes to create a new movement for the global Hmong 'which will bring Hmong together from all the different countries' based on his own creative combinations of the history of the Hmong contained in 
funeral and wedding rituals. This flag is divided into three parts by a chevron on the left side, pointing outwards towards the right. Inside the chevron it is coloured green. From the point of the chevron runs a horizontal line dividing the remainder of the flag, on its right side, into an upper and a lower half. The upper half is coloured red and says 'Xob' (the name of the Thunder God in Hmong); the lower half is blue and says 'Zaj' (which means 'Dragon', and there are many Hmong stories about the Dragon King). In the middle of the bit on the left, inside the chevron, there is a sort of a sun in the form of a smiling face with two eyes, surrounded by stars. This attempt at representing a Hmong national consciousness by a member of the younger generation is similar to the web statement, with another newly designed Hmong flag, put up by a young Hmong college student in the United States, which I have reported on elsewhere (Tapp 2003).

In Melbourne we had interviewed a shamaness whose son (whom we also interviewed) was a follower of the Chao Fa resistance messianic movement in Laos and Thailand. Another follower we interviewed had erected a substantial plaque in the same style as that pioneered by this movement, with local government assistance, which had then been vandalised. Our informants on these movements ranged from ex-soldiers (many of whom had no time for the religious aspects of the Chao Fa movement) to teenagers, and included women as well as men. Without a doubt these are minority efforts and are far from representative of the great and overwhelming majority of Hmong settlers overseas - well, let us say it clearly, they are unrepresentative. Yet that they should occur at all, when considered in the light of the younger generation's very general loss of interest in or commitment to Hmong tradition, and explicit attempts all over the world, from California to Thailand as well as in Cairns, Sydney and Melbourne, to inculcate the younger generation with Hmong values, Hmong traditions and Hmong customs, is I think deeply significant and indicative of a genuine cultural crisis among the Hmong community.

\section{Internet Usage}

In terms of one of the original project goals, to contribute a model linking and integrating local with global data, the aspect of our 
project which concerned internet usage by the Hmong has been particularly important. The aim has been to map Hmong connections on the internet and World Wide Web, to conduct interviews with those who have produced and used them, and those who have not, and to pay particular attention to the role of electronic mail and online chat shows, and where appropriate computer role games and video conferencing, in knitting together a divided and fragmented community who have dispersed to the four quarters of the globe.

Before our fieldwork in Australia, it was already clear that internet/computer usage, while significant in most Asian field sites, had not been extensive in any of them, while in Australia internet usage proved predictably to be far more extensive than in the Asian sites. Internet usage thus related directly to the developmental profile of the nation-state concerned; it was least developed among the Hmong in China, significant but often covert and not widespread in Laos and Vietnam, rapidly expanding in Thailand and very well established in Australia as, we imagine, in other First World countries - with the probable exception of France. Similarly to return visits by the Hmong to homelands in Laos and Thailand, then, internet usage represents only a small proportion of the population, and yet it has clearly had a significant impact on the evolution and maintenance of international relations and the initiation of new contacts among the Hmong.

It did seem from our interviews in both Melbourne and Cairns, that what may be more important than relations established through the internet between Asian homelands and First World countries, is relations between Hmong in those First World countries themselves; in other words, the internet and other new means of communication may be far more prominent in forging new relations and re-attaching connections between Hmong communities in France, the United States and Australia than between those in these countries and in Asia. The regional limitations of this project forbid further extensive inquiry into this or verification; however, the Australian data went some way towards suggesting that this may be the case. While there were internet contacts with Hmong in China, in some cases followed by 
visits to China, and a few with Hmong in Laos and Thailand, the overwhelming majority of internet contacts took place with other Australian, or American Hmong.

The mapping of Hmong connections on the web and internet proved more difficult than anticipated and was mainly accomplished through the use of research assistants in Australia (after the use of ASTRA programming to map the major Hmong web sites and the relations between them), and an analysis of the 25 most popular Hmong web sites and online forms based on votes coming into the list, supplemented by interviewing with users and webmasters. ${ }^{11}$

Interviews with young people and elders about internet usage showed fairly extensive use by both teenage and young adult men and women of the internet and email and chat-rooms, but only some of this was Hmong-related and little of it related to the Hmong in Asia. Interviews with webmasters and technical pioneers illuminated something of the way the Hmong internet began and has become by now extremely well established. For example, one webmaster in Melbourne said that he had been originally directly inspired by the idealism of John Naisbitt's book (1995), Global Paradox, and its McLuhanesque argument that we are moving to new world of tribalism precipitated by the internet in which nation-states would become irrelevant. A relative of his at Monash University had started Laonet, a news-oriented Lao website, and with the help of another relative at the Royal Melbourne Institute of Technology, who had supplied him with a high-speed connection, he had then joined Laonet himself and searched for specific information on the Hmong. In the initial phases, considerable assistance was received by the Hmong in Australia from American webmasters, mostly college students, such as Craig Rice of the Hmong Homepage, who had pioneered Hmong sites in the United States, in just the same way as, now, Thai Hmong are requesting assistance with setting up websites from these Australian Hmong.

In this way, and originally with the use of a hand-held scanner, the Hmong Australia Resource Page website was born, and later a discussion group (the Hmong Language Users Group, 
or HLUG) through an internet service provider a friend had established, which they now run free through Yahoo. Instrumental in these activities has been a group of intermediary migrants who had arrived in Australia prior to the refugee exodus from Laos. This group of highly educated middle-aged Hmong, less involved in the wars of Laos than their compatriots, have been uniquely well positioned to undertake this sort of activity, since they are neither of the generation of older fighters who experienced defeat and exile from Laos, nor of the younger educated generation of Australian Hmong who are less in touch with their cultural backgrounds.

A larger research question, or hypothesis, informed our internet inquiries and the fieldwork related to this; does usage of the web and internet by Hmong in different countries to contact each other signify the forging of a genuinely globalised communal diasporic voluntary public culture identity for the Hmong, or should we regard these attempts as limited, fragmentary, partial and virtual attempts to resurrect a sense of community unity which has in fact been irrevocably fragmented by global dispersal imaginary or fantasmic attempts, that is, to compensate for de facto social fragmentation? There are philosophical issues here which may be irresolvable, and which reflect debates on the role of art and ideology in relation to society. Mimetic reflection, or means of imaginative transcendence?

On the basis of the data we have collected (and continue to collect), we are now in a good position to shed some light on this general question, at least with regard to the Hmong global community. For example, it appears to us (although fuller confirmation of this would require further fieldwork in the United States and France), that hegemonic American Hmong voices are only partly dominating the internet (but see Julian, this volume); in fact a wide diversity of Hmong voices are speaking through these media, as can be seen in the furious arguments which have taken place on the Hmong internet about, for example, gender and religion. The fieldwork in Australia together with the results of our internet-based inquiries mainly confirmed results which had become apparent from earlier research in Thailand on similar issues, which suggested that a whole range of different kinds of 
appeal (Christian, conservative, rationalist, and so on) are being made to the supposed global unity of Hmong society. In one example of this, the group of messianic Hmong who use a particular mystic script for writing the Hmong language (for which fonts have now been made available on the Web; see http://hmong.scriptmania.com/phistory.htm) had recently approached HLUG for permission to use their script in discussions through HLUG. After extensive debate this was allowed, but with the proviso that the romanised alphabet generally used for Hmong (RPA) should remain the main medium of communication. In this way one can see how the Hmong parts of the internet and world wide web in fact function to reflect real schisms and divisions of a society rather than function to overcome or transcend them; a vital mirror of the social worlds, in which conflicts are played out and moral choices must be made (like attitudes towards the Amu movement, or the breakaway Hmong Council) which themselves express wider issues of cultural liberality and tolerance and definition.

\section{Conclusions and Discussion}

This research project was originally based on the assumption of major economic transformations of Asian homelands as a result of return migrant visits, and the use of the internet in facilitating the emergence of a new form of global voluntary public diasporic culture. However, it has revealed the internet more as a reflection of society than as a means of transcending social forces; the diversity of the Hmong community apparent in the real world is only too clearly reflected on the internet. While many appeals to a global Hmong unity are made, on the internet as in political and cultural life in reality, these emanate from different groups within the Hmong community and are often at odds with each other. Reverse migration and tourism to Asian locations have certainly taken place, but only among a small minority of the older overseas population, and while these encounters have led to new international linkages and alliances, in each particular national location, social, political and economic forces have acted as severe 
constraints and brakes on the emergence of a genuinely diasporic community. At the same time, while Asian locations have not been substantially transformed as a result of these visits, their impact and the impact of the financial support which Asian Hmong receive from overseas Hmong has been significant in transforming Hmong perceptions of the outside world, leading to transformations of the Hmong cultural heritage and outlook at the local level.

In Australia, as also we hypothesise in other First World locations, the trend towards assimilation and loss of the Hmong identity is overpowering, particularly among the younger generation whose command of the Hmong language and knowledge of traditional Hmong customs is a source of continuing concern to the older generation. Where transnational marriages do take place, they tend to reverse this trend; thus an Australian Hmong, with better English language skills than Hmong language skills, marrying a French Hmong, with better French language skills than Hmong language skills, may well find themselves communicating most effectively in Hmong, and in this way reversing the trend towards loss of linguistic and cultural identity. However, while these liaisons are a source of conversation and debate among the Hmong community, they take place very infrequently in comparison with the majority of marriages which take place among Hmong populations within nation-states, and therefore do not counteract the prevailing trend towards assimilation.

This trend towards assimilation correlates with disinterest towards the homelands in Asia, and even positive antipathy towards the idea of revisiting places which are felt to be backward and 'dirty'. Our fieldwork in Australia pointed clearly towards the conclusion that there was more interest in visiting Hmong communities in First World locations such as France and the United States, than in Thailand, Laos or China. There is still, among many of the younger generation, an interest in the Hmong identity and a sense of its importance, which is expressed in the fact that the overwhelming majority of marriages take place with other Hmong rather than with members of other cultural groups. 
The need to find Hmong partners is a factor in the use of the internet by the younger Hmong community, and even by some of the old, but one is far more likely to find young Hmong in Cairns chatting with young Hmong in Sydney, Melbourne, or the United States, than with France or any Asian location, because of the fact that they can communicate in English.

Nostalgia remains important among many of the older generation, but this is more often appeased by watching Hmong videos or reminiscing about the past than in actual return visits or the use of the internet. Where return visits to Asian locations take place, these are most likely to be for a variety of practical reasons than for purely nostalgic motivations; among these motivations, by far the most common private motivation was the need to visit close relatives. But medical reasons also played a significant part in motivating these return visits.

Although further research is needed, at the moment it seems as though a significant transnational public Hmong community is emerging, albeit one badly fractured through political and religious schisms, among elite members of Englishspeaking nations; in particular Australia and the United States, and to some extent Canada. While nostalgia will probably always continue to draw some overseas Hmong back to revisit their ancestral homelands in Laos and even China, and nostalgia will continue to play an important part in overseas support for the Hmong within Laos, it is likely that domestic social, economic and political factors associated with particular nation-states will continue to play a determining role in facilitating or discouraging transnational Hmong flows and contacts of people, objects, signs and capital, as they also will in facilitating or discouraging Hmong assimilation and adoption into the countries of their new settlement. At the moment it is possible to find, as we found in Melbourne, a family with brothers settled in France, Australia and the United States, all in close contact with one another through a series of affinal connections, frequent visits, and the internet, and in close contact with other near relatives in Laos and Thailand. From such evidence it would be pleasing to imagine the future of the Hmong as a transnational community transcending the 
boundaries of traditional nation-states and forming a new kind of voluntary public diasporic community. However, our research shows that such cases are in the minority and do not appear to represent the dominant trends among the international Hmong community. While exciting and novel transnational contacts have been and are taking place, the practical constraints on these are too great for these to form a credible model of future trends.

While letters, cassette tapes, video tapes, and email are used to maintain transnational Hmong contacts and to initiate new ones, the majority of such contacts do take place between Hmong who are in different developed countries, such as the United States, Australia, and Canada. Similarly the greater majority of overseas visits seems to take place between Hmong in these countries. Thus the transnational Hmong community which is emerging through international travel and the use of modern means of communication is largely a community of the developed world, which to a great extent excludes Hmong from the developing countries.

While the global unity and reunion of the dispersed Hmong community remains an ideal and a hope for many Hmong, young and old, in the developed and developing worlds, the emergence of a global transnational Hmong community - a Communal Diasporic Voluntary Public Culture — is limited on the Web, as it is in real life, by a variety of social, political and economic factors. Many people in north Queensland and Melbourne told us they would like to go back to see Laos but had no money to go back, or had tried to but had had their visas refused. Moreover, the emergence of a global Hmong community of a unitary kind is prevented not only by practical constraints (mainly political or economic), but by the very real diversities of opinion within the Hmong community of a social nature, which make their presence felt on the Web as they do in real life. Thus there are differences between messianic and rationalist Hmong, those who believe in women's liberation and those who do not, those who support the resistance struggle in Laos and those who do not, Christian Hmong of various persuasions and those who follow traditional shamanic practices, besides the growing number of younger Hmong who have no interest in such issues. 
What emerged very clearly from our research was the continuing importance of kinship in the lives of the overseas and Asian Hmong. Most visits took place to relatives, most new contacts were initiated by appeals to 'fictive' kinship, or the establishment of quasi-close kin relations based on clan surnames. The patrilineal descent system is often blamed, by Hmong themselves, for the divisions within the Hmong community which led to civil war in Laos, and there are isolated cases of attempts to overcome and reform it - by, for example, adopting a particular family name rather than a clan title as one of our informants in Melbourne had, ${ }^{12}$ or in the attempts to establish new temples and centres and forms of worship which would unite Hmong from different clans, in Australia as in Thailand. Yet most young people even in Australia were still concerned to marry other Hmong, and to avoid breaking the incest taboo which operates between different clans. The extension of fictive kinship across the world, so that kin terms can be used between a Chinese and an Australian Hmong who had never met before, simply on account of their clan names, shows that from the point of view of kinship the Hmong already form a 'virtual community' (Pao 2002); the kinship system transcends the boundaries of place and can operate anywhere. The power of kinship was also shown in the many tragic tales of siblings, couples and children and parents divided from each other through the refugee exodus from Laos, and forces attention on the mechanisms these parted relatives have evolved for staying in touch. These include visits, economic cooperations, telephone calls and the internet. Yet real proximal kinship is inevitably damaged by long distance, and here it was often the case that actual kin relations were replaced by fictive or virtual ones.

If kinship, it might be argued, provides a traditional means whereby spatial distances can be overcome and vanquished, the internet provides a new means whereby separations can be overcome and new contacts established, and this inevitably plays a part in knitting together the transnational Hmong community as a community with an individual voice of its own. There is no doubt that such a transnational community is emerging. However, our research made the strong divisions of the Hmong community very 
clear, in particular between the newly educated, born overseas and largely English-speaking Hmong, and those who have remained in Asian locations. A further separation was observed between French-speaking overseas, and English-speaking overseas Hmong. It seems possible that in the future these divisions will become more apparent and more difficult to overcome, either through the traditional means of the kinship idiom or through the use of new technologies of transportation.

In broader theoretical terms, this project has shown the strength of the nation-state in curbing the emergence of transnational diasporic communities, and the power of local social, political and economic constraints in limiting the emergence of a genuinely powerful global public culture. It has also confirmed the association between overseas elite diasporic individuals and the support for conservative or insurrectionist movements of nationalism in their homelands which other research has pointed to. The importance of kinship in channelling, guiding and informing transnational relations has been demonstrated, as well as the continuing resiliance of local places to redefine themselves in the context of broader global influences. The internet, as used by a minority of educated Hmong and particularly young people in developed countries, has been generally seen not as a vehicle for overcoming current practical or material constraints, so much as a means of communication and source of information closely reflecting the realities of social life. And while nostalgia is certainly a motivating factor in powering the returns to Asia there have been, it is by no means the only one and should be considered together with a variety of other practical reasons for revisits, in which the importance of the kinship system, as another spacechallenging mechanism, stands out as primary. 


\section{Further research}

At the conclusion of our fieldwork in Australia, although we have indicative and suggestive materials which we feel confident may be generalised to other locations in Australia and probably overseas to Hmong communities in developed countries like France, the United States or Canada, we became very aware of the need to undertake much grander surveys of the Hmong population, in regard, for example, to the direct relation between internet usage and overseas visits postulated in the original proposal (for which a default hypothesis was that the one might preclude the other), than the research techniques under this project have allowed. Indeed for the further development of a proper model combining local with global data, it may well be more appropriate to combine the traditional techniques of social anthropology (which can of course cover cultural and economic fields) with those of sociology and cultural studies. A combination of questionnaires with telephone interviewing would have allowed us to cover other Hmong populations in Brisbane and Hobart, for example, and to confirm or modify the conclusions arrived at from the data collected in Sydney, Cairns and Melbourne. Further similar surveys conducted in France or the United States would further have established how unique the Australian data is, or alternatively how representative it may be of other developed countries. 


\section{Footnotes}

${ }^{1}$ Then known as the Colombo Plan for Cooperative Economic Development in East and Southeast Asia.

${ }^{2}$ Most lease on four-year leases from local landlords.

${ }^{3}$ With thanks to Maria Wronska-Friend for clarifying this for me, and for general comments on this chapter.

${ }^{4}$ Fieldwork was conducted also in Melbourne, and where appropriate I have included some of this data.

${ }^{5}$ This was formed after a conflict over the election of a Hmong Association president (later rescinded) whose wife was Laotian and who had close contacts with the Lao Association in Australia.

${ }^{6}$ I use the RPA transcription system, in which final consonants are not pronounced, but indicate tones, and doubled vowels indicate final nasalisation.

${ }^{7}$ Compare Wang (1998-99), who found households ranging from one to nine and an average of 6.1 members per household

${ }^{8}$ Some of those who were taken to the United States as children are now themselves adult; they have been included in the total population but not in the numbers of those who made overseas visits.

${ }^{9} 26$ baht $=1$ Australian Dollar.

${ }^{10}$ This case, which involved four business-related trips to the United States but none to Southeast Asia, is not included in those listed above.

${ }^{11}$ My great thanks to Yeu Lee, Canberra, for assistance on this project

${ }^{12}$ See Leepreecha (2001) on the effects of the adoption of Thai surnames by the Hmong in Thailand. 